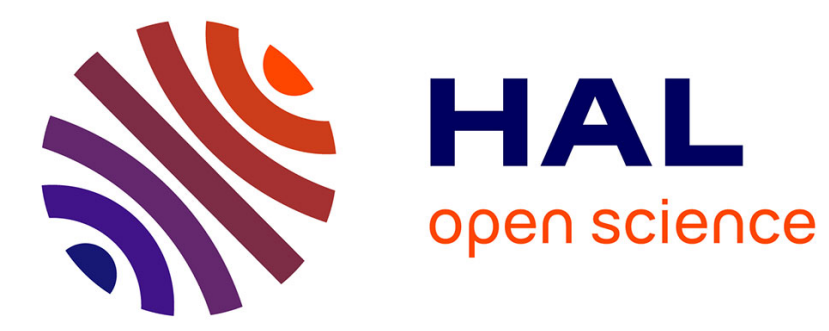

\title{
High temperature durability of a bond-coatless plasma-sprayed thermal barrier coating system with laser textured Ni-based single crystal substrate
}

Robin Kromer, Jonathan Cormier, Sophie Costil, Damien Courapied, Laurent Berthe, Patrice Peyre

\section{To cite this version:}

Robin Kromer, Jonathan Cormier, Sophie Costil, Damien Courapied, Laurent Berthe, et al.. High temperature durability of a bond-coatless plasma-sprayed thermal barrier coating system with laser textured Ni-based single crystal substrate. Surface and Coatings Technology, 2018, 337, pp.168-176. 10.1016/j.surfcoat.2018.01.006 . hal-01942731

\section{HAL Id: hal-01942731 \\ https://hal.science/hal-01942731}

Submitted on 3 Dec 2018

HAL is a multi-disciplinary open access archive for the deposit and dissemination of scientific research documents, whether they are published or not. The documents may come from teaching and research institutions in France or abroad, or from public or private research centers.
L'archive ouverte pluridisciplinaire $\mathbf{H A L}$, est destinée au dépôt et à la diffusion de documents scientifiques de niveau recherche, publiés ou non, émanant des établissements d'enseignement et de recherche français ou étrangers, des laboratoires publics ou privés. 


\title{
High temperature durability of a bond-coatless plasma-sprayed thermal barrier coating system with laser textured Ni-based single crystal substrate
}

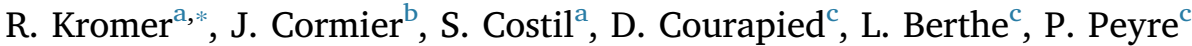 \\ ${ }^{a}$ ICB-LERMPS UMR 6303, Univ. Bourgogne Franche-Comté, UTBM, F-90010 Belfort, France \\ b Institut Pprime - Département de Physique et Mécanique des Matériaux UPR CNRS 3346, ISAE-ENSMA, Téléport 2, 1, avenue Clément ADER BP 40109 86961 \\ CHASSENEUIL - FUTUROSCOPE, France \\ ${ }^{\mathrm{c}}$ Processes and Engineering in Mechanics and Materials Laboratory (PIMM), CNRS-ENSAM ParisTech, 151 Bd de l'hôpital, 75013 Paris, France
}

\section{A R T I C L E I N F O}

\section{Keywords:}

Laser texturing

Thermal barrier coating system

Oxidation

Mechanical adhesion

Creep

\begin{abstract}
A B S T R A C T
Thermal barrier coating systems are usually build-up with bond coats to ensure a good adhesion of the ceramic top coat and to protect the substrate against oxidation and corrosion. Such system is often subjected to complex thermo-mechanical loading. Because of the very different damage processes encountered during service operations, a simplified system was investigated by removing the bond-coat. Recently adhesion bond strength was enhanced using laser surface texturing of the substrate in thermal spraying processes. Atmospheric plasma spray yttria-stabilized-zirconia thermal barrier coating system was deposited on the Ni-based AM1 single crystalline superalloy without bond coat. Adhesion bond strength was already increased compared to conventional processing method. Top coat durability was evaluated at high temperature and damage mechanisms were studied. Isothermal and cyclic oxidation tests showed durability of $1000 \mathrm{~h}$ and 400 cycles at $1100{ }^{\circ} \mathrm{C}$. The oxidation mechanisms at the substrate/top coat interface changed due to fast solidification during the laser texturing process. Then, TBC system was studied under high temperature mechanical solicitation in tension creep. The textured interfaces were not damaged after $1 \%$ creep strain while top-coat/substrate interfacial cracking was observed for grit-blasted specimens. Moreover, no preferential crack development in the substrate was observed. Patterns provided an enhanced adhesion by changing the stress distribution near the interface.
\end{abstract}

\section{Introduction}

Thermal barrier coatings (TBC) are widely used on nickel-based superalloys substrates submitted to prolonged exposures to combustion gases at high operating temperatures in order to increase gas turbine efficiency and to limit hot corrosion and oxidation issues [1]. A typical TBC system is consisted of three layers: a metallic substrate (generally, a Ni-based superalloy), an alumina-forming metallic bond coat and a ceramic top coat [2]. The bond coat has two main functions: protection of the base material against oxidation and corrosion attack during high temperature exposure and providing good adhesion of the ceramic top coat [3]. The latter protects the base material from heat of the flowing combustion gases [4]. Nevertheless, premature failures due to several mechanisms still limit the TBC systems durability [5]. Damage mechanisms in TBC systems under service conditions are complex and the crack initiation and subsequent propagation, often related to the bond coat strength and microstructure evolutions [6-8]. Macroscopic spallation is triggered by maximum in-plane compressive stress and the decrease in ceramic/metal interface bond strength due to aging effects
[9]. Interfacial damage is a combination of microstructure evolution and oxide growth. Both are thermally activated and the thermal stresses may modify the interface roughness depending on top coat structure and material. The main damaged mechanisms associated to oxidation and roughness increase are called rumpling, and consists in local interfacial delamination [10]. The elastic and plastic stored energy in the TGO (Thermal Growth Oxide) and imperfections in its vicinity play a significant role in the durability of the full TBC system under cyclic oxidation. In addition, any energy release rate of topcoat, for instance interface defects, play also a major role. The failure occurs through a sequence of crack nucleation, propagation and coalescence events during thermo-mechanical loading applied during service operations in gas turbines [11]. Under high applied stress conditions, a failure mechanism at substrate/bond coat interface may also be observed due to large creep strains and fast creep deformation of the bond coat at high temperatures above the ductile-brittle transition temperature (DBTT) [12]. Since NiAl(Pt) type bond coats have generally poor creep resistance, a TBC system without bond coat was investigated in the present study. With such a "bond-coatless" TBC system, a mechanical

\footnotetext{
* Corresponding author.

E-mail address: robin.kromer@gmail.com (R. Kromer).
} 
anchoring was used to ensure a good adhesion of the top-coat to the substrate and an alumina-forming superalloy was chosen. For this, a substrate surface laser patterning was used [11]. As presented previously, the patterns increased the in-contact area and provided mixedmode failures to obtain cohesive failures locally [14]. Thus, the adhesion bond strength of the thermal barrier coating was tripled with laser surface patterning prior-treatment compared to a standard preparation technique (i.e. grit blasting). In the present investigation, the durability and failures mechanisms of this new thermal barrier coating system without bond coat were investigated during isothermal and cyclic oxidation experiments as well as during isothermal creep tests. Yttriazirconia top-coat was deposited on a single-crystal superalloy substrate and this TBC system was investigated during high temperature oxidation and creep conditions corresponding to possible high or intermediate pressure turbine blade and vanes applications as well as high pressure turbine shrouds. A specific attention will be paid to the role of substrate laser texturing in the damage development.

\section{Experimental procedure}

\subsection{Materials}

As referred to useful TBC systems, the studied system is composed of a plasma-sprayed YSZ top coat deposited on an AM1 single crystal superalloy substrate. The AM1 is a first generation nickel-based superalloy, whose composition is given in Table 1 . Before machining the specimens, single crystalline bars were solution treated at $1300{ }^{\circ} \mathrm{C}$ for $3 \mathrm{~h}$ followed by air cooling and aged at $1100{ }^{\circ} \mathrm{C}$ for $5 \mathrm{~h}$ followed by air cooling and at $870{ }^{\circ} \mathrm{C}$ for $16 \mathrm{~h}$ followed by air cooling [15]. Buttons were machined from single-crystalline bars with a diameter of $14 \mathrm{~mm}$ and a thickness of $1.5 \mathrm{~mm}$. The coated surfaces of these buttons were closed to a (001) crystallographic plane. Creep specimens were also machined from $20 \mathrm{~mm}$ AM1 bars. These specimens were machined with the stress axis close to a [001] crystallographic orientation (deviation $<5^{\circ}$ ). Creep specimens had a gage length of $14 \mathrm{~mm}$ and a diameter of $4 \mathrm{~mm}$.

Before thermal spraying, theses specimens were treated by conventional and laser processes. First, grit-blasted surfaces (GB) were used to create a controlled roughness with abrasive-granules ( $\mathrm{Ra}=3 \mu \mathrm{m}$ ) as a reference. Second, laser surface texturing (LST) was carried out with a pulsed fiber laser (Laseo, Ylia M20, Quantel France). The laser operates at a nominal wavelength of $1.06 \mu \mathrm{m}$ with a pulse duration of $100 \mathrm{~ns}$, a maximum power of $20 \mathrm{~W}$ and variable frequency between 20 and $100 \mathrm{kHz}$. The laser beam is circular (diameter of $60 \mu \mathrm{m}$ at the focal point) with a Gaussian energy distribution. Laser patterning consists of series of equidistant lines covered with holes. Several shapes can be defined depending on the X-Y scanners and the number of pulses used. So, the textured substrate has an adhesion area depending on the shape, height, orientation, distribution and density of holes. Optimal pattern dimensions were chosen depending on the spray process (powder size and material viscosity) [16]. The density of holes has been chosen to be 100 patterns $\mathrm{cm}^{-2}$ to have optimal adhesion strengths [17]. Two hole patterns (defined as $S\{D\}$ ) were formed with an outer diameter $\{D\}$ of 60 and $80 \mu \mathrm{m}$ and a depth of $40 \mu \mathrm{m}$ for each pattern. So, three substrate topographies were created: GB, S60 and S80 (Fig. 1). The in-contact area ratio (which represents the ratio in contact between the coating and the substrate per surface unit) were evaluated to $1.8,2.7$ and 3.1 as presented [16].

Table 1

AM1 composition (wt $\%$ ).

\begin{tabular}{lllllllllll}
\hline & Ni & Co & Cr & Mo & W & Ta & Al & Ti & C & Fe \\
\hline Min & Bal. & 6 & 7 & 1.8 & 5 & 7.5 & 5.1 & 1 & - & - \\
Max & Bal. & 7 & 8 & 2.2 & 6 & 8.5 & 5.5 & 1.4 & 0.01 & 0.2 \\
\hline
\end{tabular}

Then, coatings were deposited using atmospheric plasma spraying with F4 torch (Oerlikon-Metco - Neuwiesenstrasse 158401 Winterthur Switzerland) and standard parameters optimized for the TBC material (Table 2). To ensure repeatability the torch has been mounted on a XYZ robot (ABB robot - Affolternstrasse $44 \mathrm{CH}-8050$ Zurich Switzerland). Samples were in rotational movement and the torch had a vertical movement for homogeneous coating deposition. Specimens were cooled down to room temperature by Air jet perpendicularly guided. YSZ powder $\left(91.3 \mathrm{wt} \% \mathrm{ZrO}_{2}\right.$, $7 \mathrm{wt} \% \mathrm{Y}_{2} \mathrm{O}_{3}$ and $1.7 \mathrm{wt} \% \mathrm{HfO}_{2}$ - Praxair - $\mathrm{ZRO}$ 236-1) was chosen as top coat. The particle size varied from $16 \mu \mathrm{m}$ to $100 \mu \mathrm{m}\left(\mathrm{d}_{0.1}-\mathrm{d}_{0.9}\right)$ with a $63 \mu \mathrm{m}$ mean particle size. The coating thickness was $300 \mu \mathrm{m}$. So, three configurations were evaluated (Fig. 1): grit-blasted and two textured substrates.

\subsection{Oxidation analysis}

A continuous thermogravimetric system was used in the present study for the purpose of quantification and understanding of the oxidation mechanisms [18]. The nature or rate-controlling oxide was monitored (the occurrence of breakaway and changes of the nature of the oxide and its thickness can be studied). The durability of our TBC system without bond coat was studied under isothermal and cyclic oxidation. The main objective was to analyze the impact of the substrate morphological patterning on the time to TC spallation. A special attention was paid to the nucleation of micro-cracking at the interface near the TGO and TGO growth. A SETSYS Evolution Atmospheric Thermo-Gravimetric Analysis (TGA) equipment (Setaram, Lyon, France) was used for long term isothermal and cyclic analysis. A robust and high performance graphite furnace offers high heating and cooling rates (up to $100{ }^{\circ} \mathrm{C} / \mathrm{min}$ across the entire temperature range) in synthetic air environment $\left(20 \% \mathrm{O}_{2}\right.$ and $\left.80 \% \mathrm{~N}_{2}\right)$. In this TGA equipment, a symmetrical and hang-down balances detected small mass changes over long term thermal analysis with a precision of $\pm 2 \mathrm{ng}$. The system was used to measure mass uptake/loss under isothermal $\left(1100^{\circ} \mathrm{C}\right.$ for $\left.100 \mathrm{~h}\right)$ and thermal cycling ( 100 cycles with $10 \mathrm{~min}$ at $100^{\circ} \mathrm{C}$ and $1 \mathrm{~h}$ at $1100{ }^{\circ} \mathrm{C}$ ) conditions. The heating and cooling rate used for the experiments was fixed to $90^{\circ} \mathrm{C} / \mathrm{min}$. Three samples were investigated for each thermal condition and surface preparation.

\subsection{LASer Adhesion Test (LASAT)}

LASAT is a laser adhesion test allowing the generation of high tensile stresses in materials. In order to produce a laser-generated showwave through a target, a high power laser irradiation is required. When it is focused on a target, the laser-matter interaction leads to an intense plasma formation [19]. As a response, a shock-wave is generated through the target. Its characteristics depend on several parameters (pulse shape, duration, and energy). A water confinement has been used to constrain the plasma expansion [20]. When the shock-waves intersect interface or free surface, it is reflected as a release wave. At the same time, a release-wave also propagates in the sample. A tensile stress can hence be generated locally close to a given interface. If tensile stresses near the interface are high enough than the debonding threshold of the interface, it generates a spallation of the coating and thus generates distinctive velocity signals of the back-face detected by VISAR (Velocity Interferometer System for Any Reflector) measurements [21]. The debonding threshold measurements only work under those specific conditions (Fig. 2). The maximum local stresses indeed need to be located near the interface of the coated system. The laser source used to perform shock-wave experiments was the HEPHAISTOS laser facility (PIMM laboratory, ParisTech, France). The laser has a impulsion time of $7.1 \mathrm{~ns}$ with a wavelength at $532 \mathrm{~nm}$ (Nd:YAG GAIAclass laser, Thales Laser, France). The beam spatial energy distribution is a "top-hat" and the pulse shape has a near Gaussian distribution. The VISAR device allows measurements of the back-face velocity and permits the identification of damage development. Three samples were 

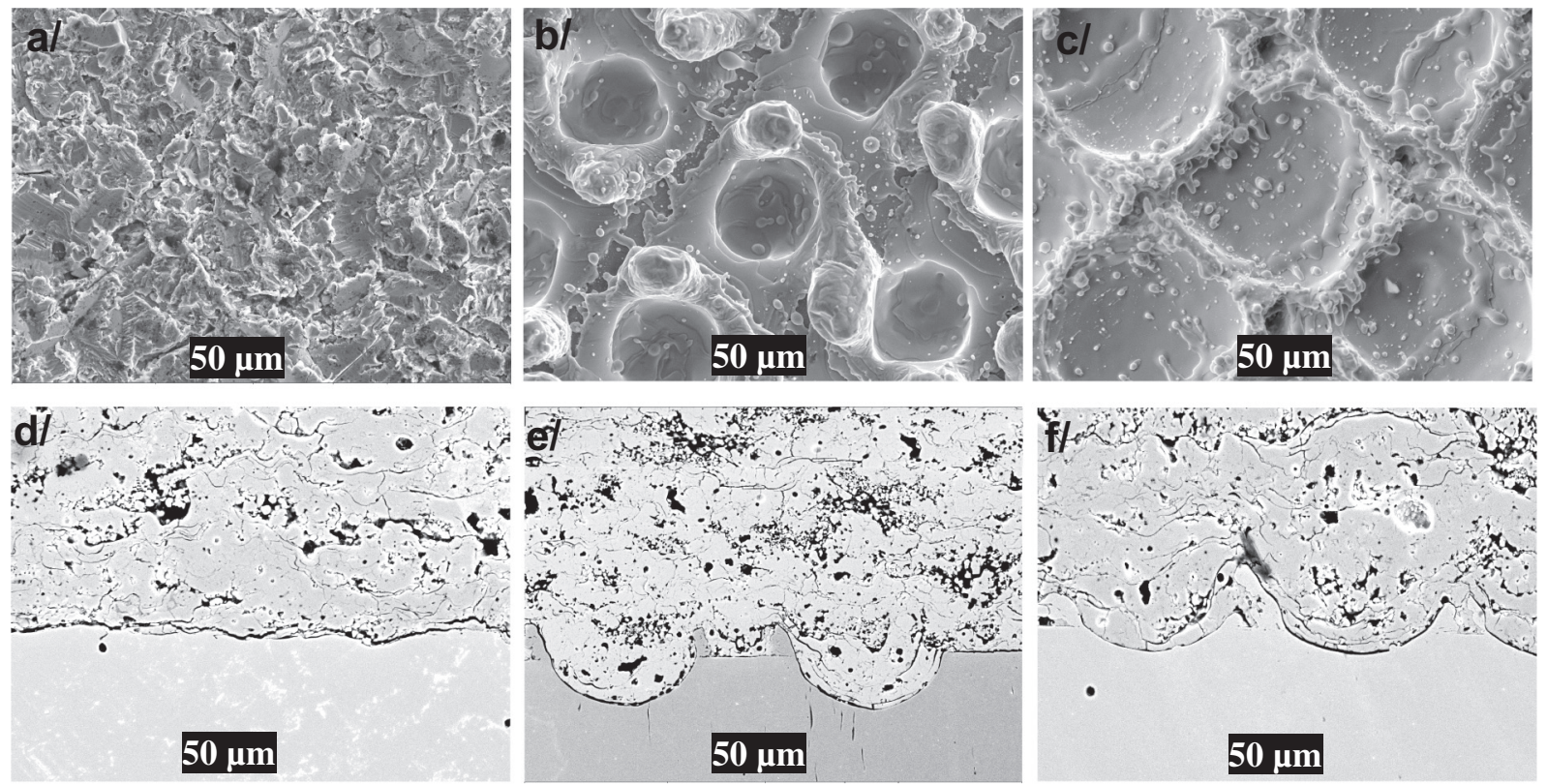

Fig. 1. Laser surface texturing strategy - top view of and cross-sections for (a-d) grit-blasted, (b-e) S80 textured and (c-f) S60 textured surfaces.

Table 2

Thermal spray parameters for top coat.

\begin{tabular}{lll}
\hline Primary gas flow rate [slpm] & $\mathrm{Ar}$ & 44 \\
\cline { 2 - 3 } & $\mathrm{H}_{2}$ & 13 \\
\hline Spray distance [mm] & 120 & \\
Arc current [a] & 630 & \\
Powder feeding rate $[\mathrm{g} / \mathrm{mm}]$ & 23 & \\
Carrier gas flow [L/min] & 3.4 & \\
Angle injection $\left[{ }^{\circ}\right]$ & 90 &
\end{tabular}

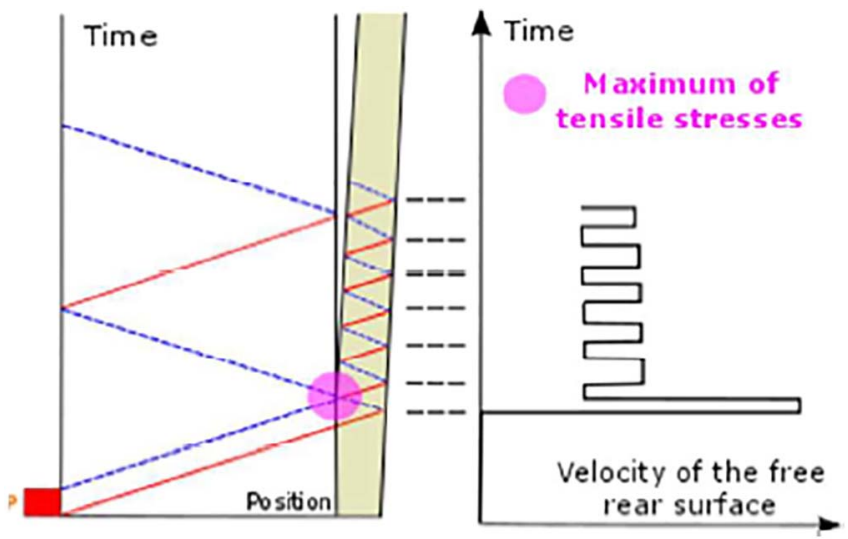

Fig. 2. Left - time/position diagram showing the shock wave propagation (red: compression and blue: tension) in a thin coated system (white: substrate and brown: coating) and the debonding of the interface; right - scheme of the corresponding velocity signal. (For interpretation of the references to color in this figure legend, the reader is referred to the web version of this article.)

evaluated for each thermal condition and surface preparation.

The same conditions were used, namely same laser spot and same coating/substrate configurations. Step-by-step, the laser energy has been increased up to reaching delamination after different oxidationtime TBC systems. A limit can be determined when the energy is sufficient for a delamination. It described the threshold of interface debonding. Three tests under and above the specific values for each specimen were performed to increase the reliability of measurements.
This test could be performed on small samples used for oxidation tests and enable a local maximum tensile stress evaluations. The defects at the interface are strongly highlighted by the dynamic adhesion tests compared to conventional pull-off tests.

\subsection{Creep tests}

Additional tensile creep tests were performed to investigate the mechanical loading and/or temperature history promoting oxide growing of the specific TBC system [22-23]. Besides, the new TBC system needs to be characterized under such thermo-mechanical conditions since several sections of turbine blades are likely to undergo viscoplastic deformation in non-sufficiently cooled sections. Creep tests were performed using a specific set-up developed at Institut Pprime (France). They were performed under constant load. Heating was ensured by a radiant furnace and displacements were measured using a contact less extensometer directly measuring the displacement of flags attached to the gage part of the specimens. The temperature heterogeneity along the gage length was $<5^{\circ}$ as demonstrated in previous publication [24]. Creep tests were performed with 120 and $140 \mathrm{MPa}$ initial applied stress at $1100{ }^{\circ} \mathrm{C}$. Tests duration ranged between few up to hundreds of hours to achieve a creep deformation closed to $1 \%$ were fixed. A creep strain generally corresponding to the very beginning of the tertiary creep stage of the AM1 Ni-based single crystal superalloy under such creep conditions was determined.

\subsection{Microscopic observations}

Specimens were observed after thermal exposures and creep tests using various scanning electron microscopes (SEM) (SEM JEOL 6400 and 7800F). EDX analyses (SEM $6100+$ Quantax EDS 6/10, Bruker and SEM 7800F + EDS-SDD, Jeol) were also used to detect oxides and $\gamma^{\prime}$ depleted layers near the top coat/substrate interface. Such characterizations were performed after careful longitudinal sectioning of the specimens and low temperature embedding in a conductive resin. Mechanical polishing up to a mirror finish was performed for all types of specimen. Several specimens were also etched using a solution made of $2 / 3 \mathrm{HCl}+1 / 3 \mathrm{HNO}_{3}$ (vol. fractions) at $4{ }^{\circ} \mathrm{C}$ to reveal the $\gamma / \gamma^{\prime}$ microstructure of the substrate. 


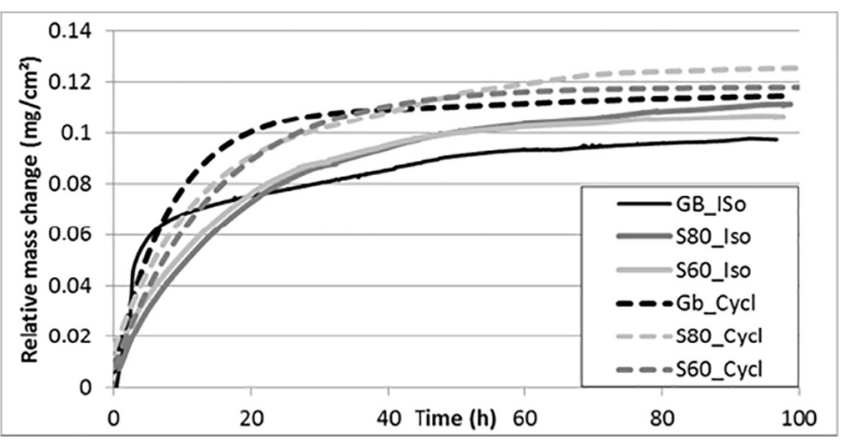

Fig. 3. Relative mass change as a function of time for isothermal and thermal cycling tests - grit-blasted (GB) and laser textured (S80 and S60) samples - errors of $0.0002 \mathrm{mg} \cdot \mathrm{cm}^{-2}$.

\section{Results}

\subsection{Isothermal and cyclic oxidation}

Isothermal oxidation at $1100{ }^{\circ} \mathrm{C}$ for $5 \mathrm{~h}$ up to $100 \mathrm{~h}$ and thermal cycling oxidation from 5 up to 100 cycles at $1100{ }^{\circ} \mathrm{C}$ for $1 \mathrm{~h}$ were performed for grit blasted (GB) and laser treated (S80 and S60) specimens. The relative mass change for isothermal and thermal cycling oxidation up to $100 \mathrm{~h}$ was plotted in Fig. 3 (continuous and dotted-lines respectively). Each single specimen's measurement is calculated per surface unit using image analysis to calculate the area exposed to oxidation. In this way, the additional area due to the presence of holes for textured specimens was taken into account knowing their morphology and the density.

First, a mass gain is observed for each specimen under both isothermal and thermal cycling conditions. Different evolutions of the relative mass change are observed, both during the first hours of oxidation and after $60 \mathrm{~h}$. Moreover, the application of a thermal cycling favors the oxidation of all the specimens by micro-cracks formation, especially for short oxidation durations (below $20 \mathrm{~h}$ ). The impact of the thermal cycling on the relative mass uptake is in good agreement with Poquillon et al. for two NiAl single crystals [25]. Then, it is also noticed that the oxidation kinetics are dependent on the surface preparation. Grit-blasted specimens present a faster oxide growth than laser treated ones for the first hours of oxidation. After about $30 \mathrm{~h}$ of oxidation, laser treated specimen always exhibit a higher mass uptake compared to grit blasted ones. The relative mass changes were low after $100 \mathrm{~h}$ or 100 cycles. It is supposed that a protective layer was grown.

Under high temperature $\left(\mathrm{T}>1000^{\circ} \mathrm{C}\right)$, it was found that the oxide film on AM1 superalloy consists of two layers (Fig. 4), i.e., an inner layer from the side of the metal substrate, which is composed of oriented grains of $\alpha-\mathrm{Al}_{2} \mathrm{O}_{3}$, and an outer layer, which comprises oriented grains of $\mathrm{NiAl}_{2} \mathrm{O}_{4}$ spinel [26]. It is also observed that the oxidation of the substrate resulted in a $\gamma^{\prime}$-depleted layer (i.e. without any $\gamma^{\prime}$ particles) as usually observed in the literature [27]. The two layers of the oxide scale are separated by discrete inclusions of tantalum and titanium oxides (bright spots in the backscattered electron image). So, multi-layer oxides were observed and the transition in oxidation behavior can be deduced with the alumina phase changes. However, the alpha alumina can be defined has a protective layer after $50 \mathrm{~h}$. Such multi-layered oxides were observed for the different specimens (Fig. 4a).

For grit-blasted samples, the plastic deformation induced by the abrasion process changed the oxide growth. $\mathrm{Al}_{2} \mathrm{O}_{3}$ oxide was the main TGO. The spinels and inclusions were not clearly defined. Moreover, cracked oxides were noticed for GB after $100 \mathrm{~h}$ (see Fig. 4b). It might be the consequences of mixed spallation: cracks propagated through TBC/ TGO or TGO/substrate interface. The misfit leads to compressive stresses and the curvature gives different stresses components. APS TBC has a lamellar structure which is not adapted to support perpendicular stresses (i.e. thermal misfit strains between substrate and TBC). For textured substrates, laser treatments promoted a multi-layered oxide scale similar to the polished substrate (Fig. 4c). Besides, the inclusions were well defined between the inner and outer layers.

\subsection{Time to spallation of the top-coat under high temperature oxidation}

Fig. 5 shows the evolution of the adhesion strength determined by the LASAT test for grit-blasted and laser textured specimens, both after isothermal and cyclic oxidation tests. Four samples were evaluated for each condition.

First the laser adhesion test allowed evaluating the interface topography effect on adhesion [28]. It was confirmed by the authors that the laser surface texturing enhanced the adhesion bond strength by mixedmode failures under quasi-static and dynamic stresses [17]. Then, after high temperature exposure, the adhesion threshold changed. For isothermal oxidation, an optimal value after $100 \mathrm{~h}$ was noticed, meaning that a high interfacial toughness is obtained after such an exposure time, as already observed previously by Vaunois [30]. The physicochemical compatibility was optimal between YSZ/TGO after $100 \mathrm{~h}$, corresponding to a TGO scale mainly composed of dense and continuous $\alpha-\mathrm{Al}_{2} \mathrm{O}_{3}$. It is suspected to be linked to a higher substrate/oxide interfacial toughness associated to the formation of a continuous and dense inner $\alpha-\mathrm{Al}_{2} \mathrm{O}_{3}$ oxide layer in the TGO. The improvement was higher for S80 due to larger in-contact area. Moreover, the adhesion strength decreased almost linearly after $100 \mathrm{~h}$ for isothermal exposure whatever the specimen type. As observed Fig. 6, GB specimens spalled (i.e. a zero adhesion threshold) after $350 \mathrm{~h}$ while S60 and S80 would reach spontaneous spallation threshold for durations in the 1500-2000 hours range.

Finally, it was shown that the introduction of a thermal cycling during oxidation tests leaded to a faster decrease of the TC adhesion. GB specimens were observed to spall before $200 \mathrm{~h}$ (spallation after 170 cycles). Larger roughness ( $\mathrm{Ra}=5.3$ and $8.2 \mu \mathrm{m}$ ) was investigated to check this behavior. The spallation time was equal to $220 \pm 30$ and $280 \pm 20 \mu \mathrm{m}$ respectively. So, the morphological patterning had a

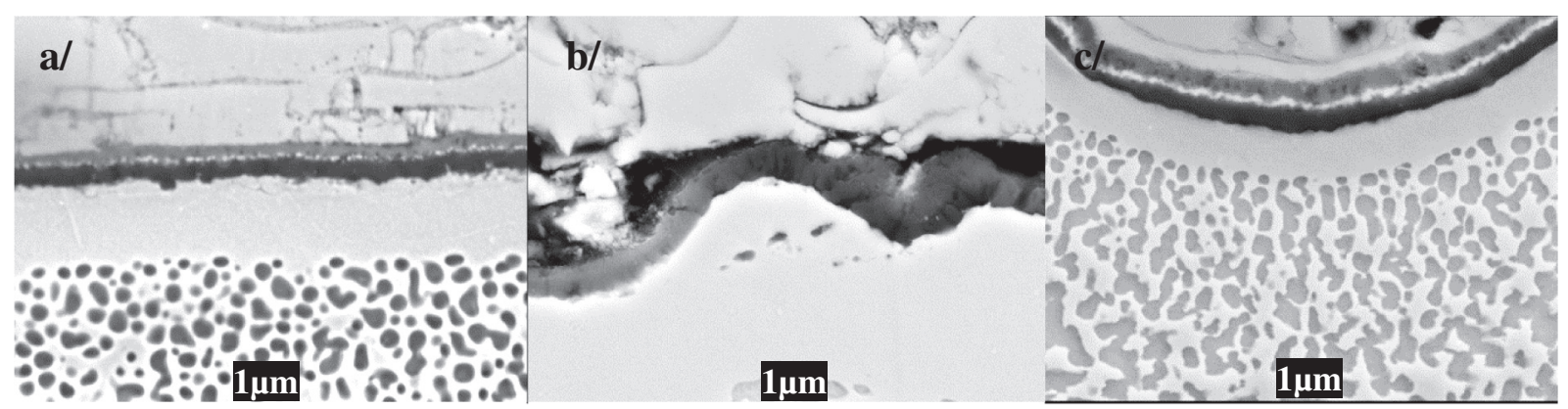

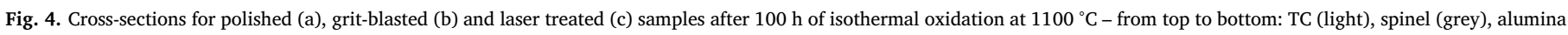
oxide (dark) and substrate (light). 


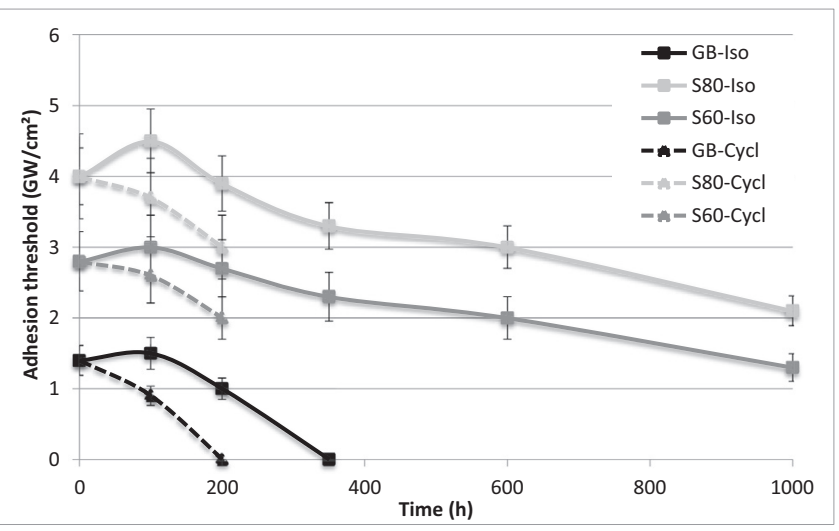

Fig. 5. Adhesion threshold for grit-blasted (GB) and laser textured (S60 and S80) specimens for isothermal (Iso) and cycled thermal (Cycl) tests - three samples were evaluated for each thermal condition and surface preparation.

strong impact on adhesion.

Even if laser treated specimens did not exhibit spallation of the TC after $200 \mathrm{~h}$ of thermal cycling, it was observed a spectacular decrease of the adhesion, hence highlighting the detrimental effect of thermal cycling. For these laser treated specimens, a TC spallation life between 400 and 500 cycles was expected (linear extrapolation from the trend presented in Fig. 5). Thermal cycling tests up to such durations would deserve to be performed to confirm this estimation.

Vaunois [30] or Liu et al. [31] presented metallographic characterizations of failure modes in plasma sprayed TBC systems evaluated in isothermal oxidation at $1100{ }^{\circ} \mathrm{C}$. It was found that the durability of commercial quality TBC system is related to progress of degradation modes of bond coat and top layer. During isothermal oxidation test, the bond coat was oxidized to form of a dense alumina and a porous mixed oxide layer between the YSZ top coat and a bond coat made of NiCoCrAlY alloy. At the moment of oxidation acceleration, the process of crack initiation and propagation was observed mainly in the mixed oxide layer near the YSZ. The observed crack propagation induced the delamination and spallation of top coat after $500 \mathrm{~h}$ oxidation. In this study, the lifespan was in the same range of our GB samples without bond coat, even if the interface roughness was lower in our case compared to these previous studies. So, laser surface texturing results can be considered to increase the lifespan under the same conditions.

Microstructure observations along cross sections were performed (see Figs. 6 and 7). Microstructures close to TC/substrate interface as presented were observed in the as-deposited state (i.e. without any high temperature oxidation), after $100 \mathrm{~h}$ of isothermal oxidation at $1100{ }^{\circ} \mathrm{C}$ and after 100 cycles in cyclic oxidation. Grit-blasting created a specific roughness by plastic deformation of the substrate and erosion mechanisms. The superalloy microstructure was hence highly deformed at the extreme surface (Fig. 6a). The compressive stresses due to gritblasting affected the microstructure during oxidation (both isothermal and cyclic oxidation) and 4 affected zones were distinguished: $1 /$ a $\gamma^{\prime}$ depleted layer, 2/ a layer showing cellular recrystallization, 3/ a transition zone and $4 /$ the substrate standard microstructure, whose $\gamma^{\prime}$ particles have coarsened during thermal exposure (Fig. 6b). The areas of cellular recrystallization were direct linked to the residual stresses introduced during the grit-blasting and are suspected to affect the TGO growth mechanisms [32]. It was noticed interfacial porosity between the TGO and the top coat promoting crack initiation areas (Fig. 6b). Cracks were indeed observed following this interface during isothermal tests. Besides, few parts of the coating stayed attach to the substrate after thermal cycling tests (Fig. 6c). The difference of thermal expansion coefficients are known to create stresses during the solidification, leading to interfacial and intersplats cracks, as observed in Fig. 6c.

LST created patterns by vaporization and recoil pressure mechanisms [33]. A melted layer with $\sim 1 \mu \mathrm{m}$ thickness can be observed in the bottom of the pattern in addition to resolidified matter on the edges (Fig. 7a). No evidence of local recrystallization was noticed in the vicinity of the keyholes created by the LST process. A continuous TGO was observed after thermal exposure but no crack initiation was clearly identified after isothermal oxidation tests. The edges were the areas where the first cracks started (arrow Fig. 7b). The maximum solicitation area was supposed on the edges during TGO growth. Therefore, damage development above the hole was observed during thermal cycling treatments (dashed-arrow Fig. 7c). It was observed on the different specimens. A compressive stress state in the hole enabled deviations of cracks in the coating [34] Thus, the time for TC spallation was limited by the coating mechanical properties due to this failure mode. Indeed, S80-textured specimens have a larger adhesion strength (see Fig. 6) due to larger cohesive area in comparison to S60 (larger section diameter), which supports this assumption.

\subsection{Creep tests}

A viscoplastic deformation at high temperature was introduced by performing tension creep tests to investigate the development of damage with the superposition of a load. It is recalled that creep tests were purposely interrupted after reaching nearly a $1 \%$ creep strain. It corresponds to the onset of tertiary creep. Also, we did not want to investigate failed specimens in which the local increase in stress triaxiality in the necking region of the specimen would affect at the coating cracking. The failure mechanisms of the TBC system involved during both long (i.e. applied stress $=120 \mathrm{MPa}$ ) and short (i.e. applied stress $=140 \mathrm{MPa}$ ) creep tests were investigated in the vicinity of the TGO (i.e. top coat/TGO and TGO/substrate interfaces). The objective was to deduce the major factor of TC spallation such as oxide growth or creep deformation. Fig. 8 shows low (120 MPa) and high (140 MPa) creep curves for grit-blasted and laser textured samples. Cross-sections after creep tests are presented in Fig. 9.

Fig. 9a and b show that an entire top coat/TGO delamination was obtained at the end of creep tests. On the contrary, patterns enabled the coating/substrate contact integrity after the creep tests with no clear

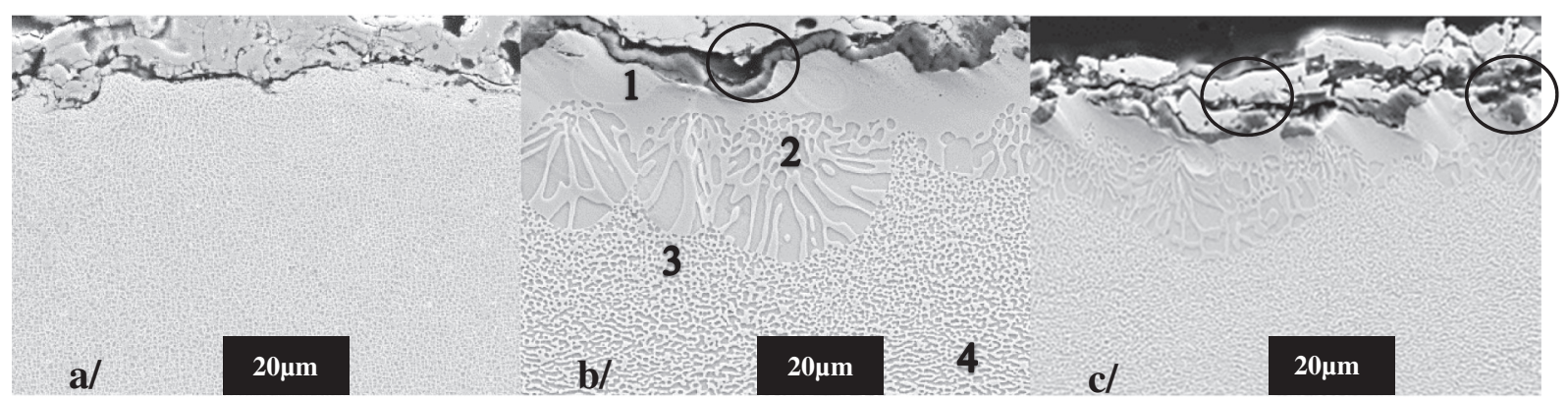

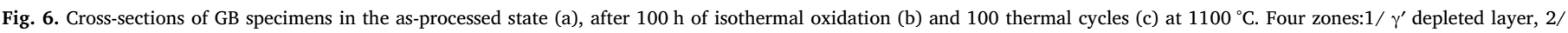
cellular recrystallization, 3 / transition zone and 4/ standard microstructure - circles identified interface porosity and intersplats cracks. 


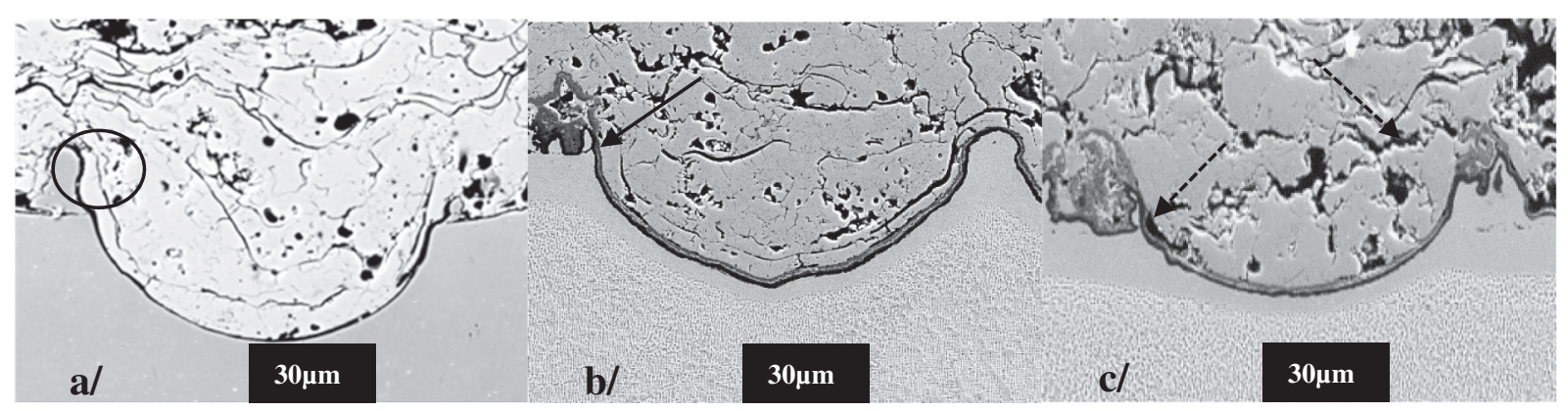

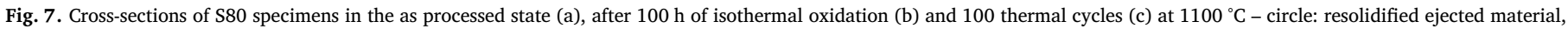
arrow: crack with isothermal oxidation, Dashed-arrow: crack with anisothermal oxidation.
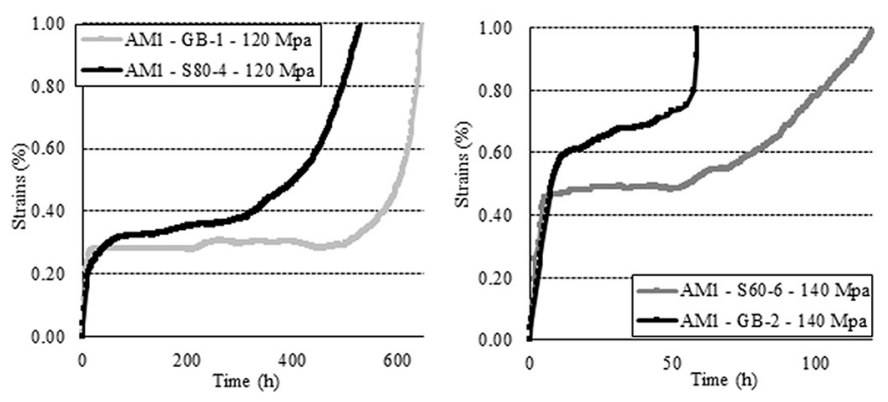

Fig. 8. Creep behavior at $1100^{\circ} \mathrm{C} / 120 \mathrm{MPa}$ (a) and $1100{ }^{\circ} \mathrm{C} / 140 \mathrm{MPa}$ (b).

proof of crack initiation in this interface (Fig. 9c and d). Laser surface texturing hence allowed a sufficient anchoring compared to gritblasting.

The creep behavior is observed to be very similar between GB (1\% creep strain in $525 \mathrm{~h}$ ) and S80 (1\% creep strain in $650 \mathrm{~h}$ ) specimens for a $120 \mathrm{MPa}$ applied stress. However, with a $140 \mathrm{MPa}$ applied stress, it is observed a pronounced decrease of the time to reach $1 \%$ creep strain for the grit-blasted specimen in comparison to the laser-textured one. The earlier onset of tertiary creep for grit-blasted specimens might be explained by the grit-blasting consequences on the extreme surface microstructure of the substrate. It was observed in the present study (see
Fig. 10) surface recrystallization after creep tests using grit-blasted specimens, due to surface compressive residual stresses present at the beginning of the tests. No recrystallization has been noticed in lasertextured specimen (only few zones on the plateau). Such a recrystallization mechanism has already been observed previously for similar creep conditions and alloys [35]. The volume fraction of recrystallized zone under tensile loading has almost no bearing capacity [36], and as a result, the actual stress acting on the unrecrystallized substrate is larger, which is the main cause for the lower creep life of GB specimen, especially for a $140 \mathrm{MPa}$ applied stress. The recrystallized zone was measured to be equal to $24 \pm 4 \mu \mathrm{m}$ for creep tests performed at $120 \mathrm{MPa}$ and $36 \pm 7 \mu \mathrm{m}$ under $140 \mathrm{MPa}$ creep conditions. Taking into account this recrystallized layer, the applied stress was estimated to be $125 \mathrm{MPa}$ instead of $120 \mathrm{MPa}$ and $147 \mathrm{MPa}$ instead of $140 \mathrm{MPa}$. It is also worth mentioning that the patterns were taken into account in the section computation as they decrease the net bearing capacity of the substrate.

For the sake of comparison, Riallant et al. [37] have studied the damage mechanisms of AM1/NiAlPt/EBPVD YSZ system under the same creep conditions. Time for $1 \%$ of deformation was evaluated to 500 and $50 \mathrm{~h}$ for this TBC "standard" system under 120 and $140 \mathrm{MPa}$, respectively. They observed YSZ/TGO delamination after $1 \%$ of creep deformation. In addition, they noticed porosity at the bond coat/substrate interface. So, for GB specimens, evidences of delamination were

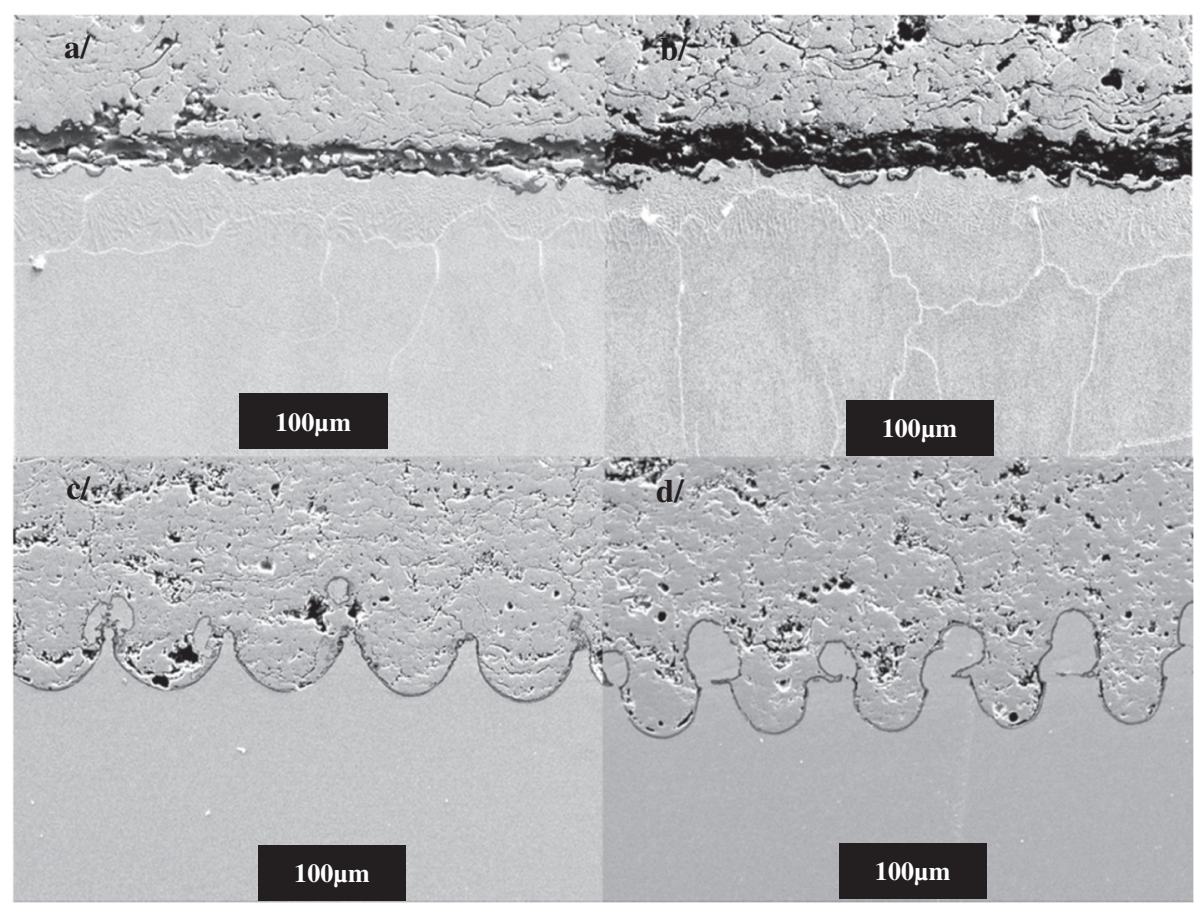

Fig. 9. Cross section observations after creep testing at $1100{ }^{\circ} \mathrm{C} / 120 \mathrm{MPa}$ of grit blasted (a) and laser textured (S80) specimens (c) and after creep testing at $1100{ }^{\circ} \mathrm{C} /$ $140 \mathrm{MPa}$ of grit blasted (b) and laser textured (S60) specimens (d). 


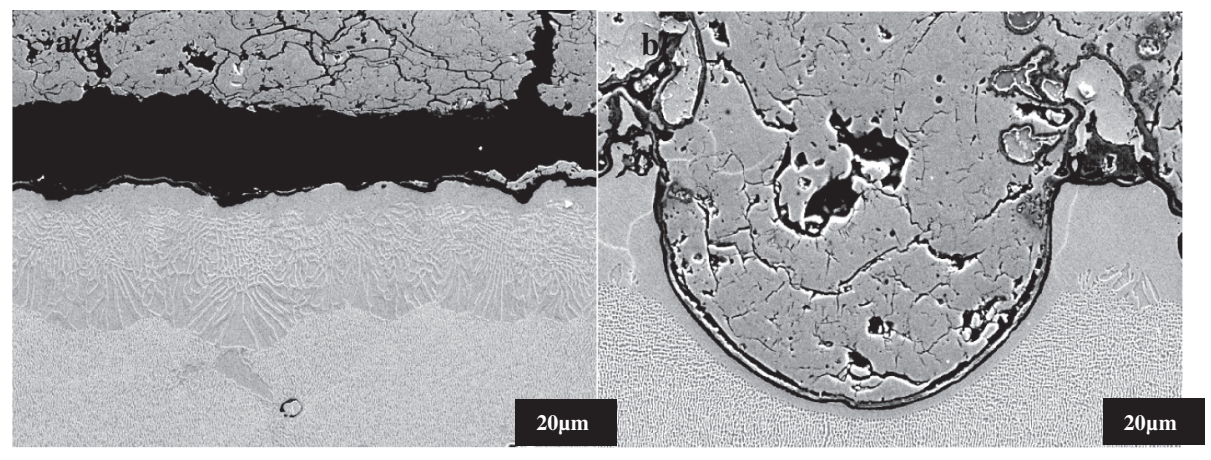

Fig. 10. Cross-sections of (a) grit-blasted and (b) laser textured (S80) after isothermal oxidation - recrystallization highlight.

observed at the interface of the oxide layer. But, for LST, no debonding was observed, whatever the creep conditions (see Fig. 10b and d). Besides the oxide layers were continuous along the patterns/coating interface. The constant applied loading has only created few cracks on the top coat extreme surface (not shown here). Finally, there were no cracks running through the substrate from the patterns, due to the local stress concentration within the substrate. Hence, this "bond-coatless" system with laser surface texturing enabled a comparable (or even better) durability under high-temperature oxidation and creep conditions.

\section{Discussion}

It has been observed in the present study that laser surface texturing seems to be a reliable process to increase the time to spallation of an APS YZS top coat deposited on the AM1 Ni-based single crystal superalloy during isothermal and cyclic oxidation, but also in creep at $1100{ }^{\circ} \mathrm{C}$. This new bond-coat-less TBC system could be considered as a good candidate for high temperature turbine blade, vanes or shrouds applications, especially if the substrate presents intrinsic good oxidation and corrosion resistances.

To explain the possible origins of this improvement in time to spallation compared to a standard grit-blasting process few arguments can be highlighted. Post-processing TGA data (see Fig. 3) to extract the mass gain rate as a function of time enabled a parabolic rate constant evaluation of grit-blasted (GB) and laser textured (S80) specimens. The variations of mass gain versus time can be fitted to a parabola according to Eq. (1) [38]:

$\mathrm{t}=\mathrm{A}+\mathrm{B} \Delta \mathrm{m}+\mathrm{C} \Delta \mathrm{m}^{2}$

The kinetics parameters can be evaluated from the coefficients A, B, and $\mathrm{C}$ obtained from such a fit. The most important feature is that the second degree coefficient $\mathrm{C}$ is always the reciprocal of the "true" parabolic rate constant $\mathrm{kp}$. The fitting of the experimental data to a complete parabola permits a correct evaluation of the $\mathrm{kp}$ value independently of the effective oxidation mechanism and/or the occurrence of a transient oxidation regime. Fig. 11 shows the evolution over time of the parabolic rate constant kp for grit-blasted and laser textured samples under isothermal and thermal cycling oxidation tests.

As presented, a transition zone can be observed before $1.7 \mathrm{~h}$ systematically. The curves decreased fast. The different regions were discussed. Raman spectroscopy analysis was used to evaluate the oxide nature (Fig. 12). The transient oxidation mechanisms can then be confirmed from a $\theta-\mathrm{Al}_{2} \mathrm{O}_{3}$ to $\alpha-\mathrm{Al}_{2} \mathrm{O}_{3}$ phase. As observed by Huang and Peng [39], based on the SEM and Raman analyses, when oxidation starts $\theta-\mathrm{Al}_{2} \mathrm{O}_{3}$ preferentially nucleates. Then, the $\theta-\mathrm{Al}_{2} \mathrm{O}_{3}$ nuclei quickly link together to form a continuous layer. Later on, the $\alpha-\mathrm{Al}_{2} \mathrm{O}_{3}$ layer grows out-ward under the control of aluminum cation diffusion and inward under the control of oxygen anion diffusion. Thereafter, the $\alpha$ $\mathrm{Al}_{2} \mathrm{O}_{3}$ develops a continuous layer at the interface. Finally, the $\theta-\mathrm{Al}_{2} \mathrm{O}_{3}$ to $\alpha-\mathrm{Al}_{2} \mathrm{O}_{3}$ transformation occurs under high temperature. The oxide volume contraction due to the phase changes can generate micro-

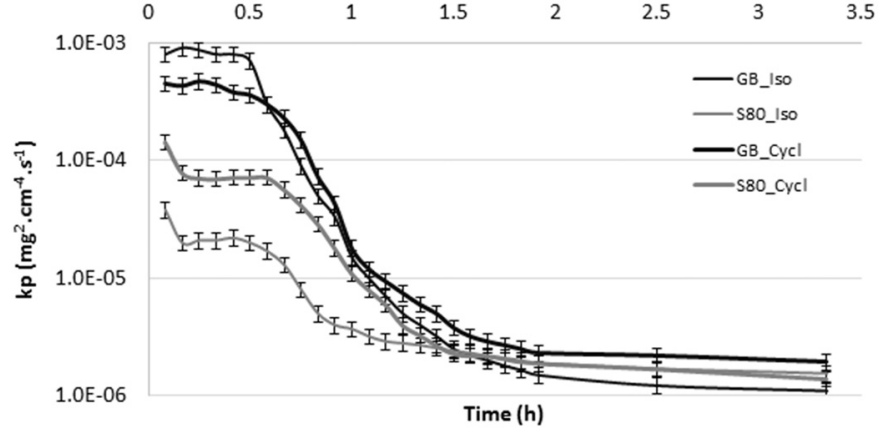

Fig. 11. Parabolic rate constant evolution for grit-blasted (GB) and laser textured (S80) samples under isothermal and thermal cycling oxidation at $1100{ }^{\circ} \mathrm{C}$ - three samples were evaluated for each thermal condition and surface preparation.

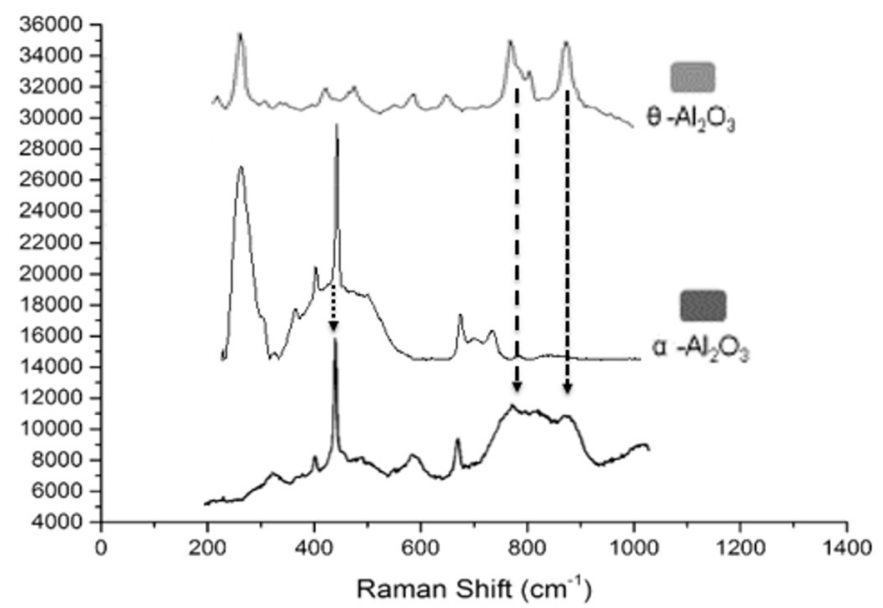

Fig. 12. Raman spectroscopy results compared to standard $\theta-\mathrm{Al}_{2} \mathrm{O}_{3}$ to $\alpha-\mathrm{Al}_{2} \mathrm{O}_{3}$ - drawing of the oxide layer.

cracks, which are visible on the patched surface. The two specific signatures were hence observed using Raman spectroscopy.

The first stage showed larger oxidation kinetics for GB than LST specimens. The surface plastic deformation induced faster oxide scale growth and it might be induced by the elastic and plastic stored energy. The concentration differences of specific element were not deduced from EDX analysis. For the second phase, the stable parabolic rate constant is not clear different for the different surface treatments. Audigié [40] shows that $\mathrm{kp}$ was equal to $9.5 \cdot 10^{-8} \mathrm{mg}^{2} \cdot \mathrm{cm}^{-4} \cdot \mathrm{s}^{-1}$ for polished AM1 superalloy at $1100^{\circ} \mathrm{C}$. In this case, kp value is lightly bigger compared to Audigié et al. REF value which can be explained by cracked oxides for GB or by spinels continuous growth for LST specimens. Thus, a protective layer can be confirmed with the kp stabilization. Near interface, stresses were supposed due to micro-cracks formation. It might be explained by the volume contraction and growth 
rate linked to the thermal tests. According to Fig. 11 where almost similar oxidation kinetics for GB and LST specimens after $2 \mathrm{~h}$ of oxidation were noticed, the differences in top coat adhesion between both type of specimen as revealed by the LASAT testing procedure may only result from the nature of the oxide scale, especially the one developed within the first hours of oxidation. Moreover, the cracked TGO as observed for GB specimens in Fig. 5b may also decrease the time to spallation under both isothermal and thermal cycling conditions.

This new textured TBC system enables a large durability by increasing the mechanical anchoring mechanisms. The patterns seem to change the distributions of crack propagation [41]. Ranjbar-Far et al. [42] have developed a numerical modeling with the finite element code ABAQUS considering a non-homogenous temperature model to study the thermo-mechanical behavior of the thermal barrier coatings system. Among many factors affecting the durability and failure mechanisms of thermal spray coatings during their service life, the residual stresses resulting from the coating process and temperature gradient play an important role. The interface topography affects the residual stress distribution near the interface. Low roughness amplitudes cause straight transversal crack paths, whereas a high amplitude roughness results in kinked crack paths (Fig. 13). Evans and Taylor [43] indeed demonstrated that the presence of a large surface roughness leads to a spatial variation in continuity strains which will result in out-of-plane tensile stresses at the exposure temperature. The development of fastgrowing non-protective oxides due to aluminum depletion (chemical failure) is developed at the tips of bond coat protuberances. It increases with the roughness modification in the cyclic thermal treatments. With flatter interfaces, delamination can proceed by growth of wedge cracks which develop along the TGO/bond coat interface during cooling.

So, oxide micro-cracks might be deduced from a large oxide growth rate after grit-blasting. For a rough interface, stresses in the top coat, TGO and substrate result from thermal expansion mismatch and TGO growth. So, damage can be accumulated near TGO-ceramic interface due to coating structure and oxide micro-cracking. Critical-size crack produces spallation due to large in-plane stresses. Therefore, for laser patterned substrate, compressive stresses were generating in pattern due to the concave shape during coating build-up. Oxides growth caused an increasing tensile stresses in the pattern while pushing the peak regions into compression. Cracks could be seen above peaks and around patterns. They propagated above concave shape due to coating lamellar structure. So, remelted material on the pattern edges could be beneficial and play a role of "snap fastener". Fig. 14 summarizes the damaging mechanisms of grit-blasted and laser textured surfaces as a function of time. The failure mechanisms could be deduced as a "buckling" mechanism for GB specimens. In addition, the fast TGO growth enabled multi-crack location. On the contrary, the top coat intrinsic toughness (inter-lamellar defects and anisotropic structure) is the life limiting factor for LST specimens. The crack propagated above the patterns and the oxide growth was smoother in this case. The lamellar structure helps the buckling mechanisms.

Finally, the TGO thickness evolution has been plotted in Fig. 15 for grit-blasted and laser treated specimens, for isothermal and thermal cycling oxidation treatments. The TGO thicknesses after creep tests have been superimposed in this plot. Parabolic curves are observed and are logically linked to mass rate changes presented previously.

It is observed that creep specimens developed thicker TGO

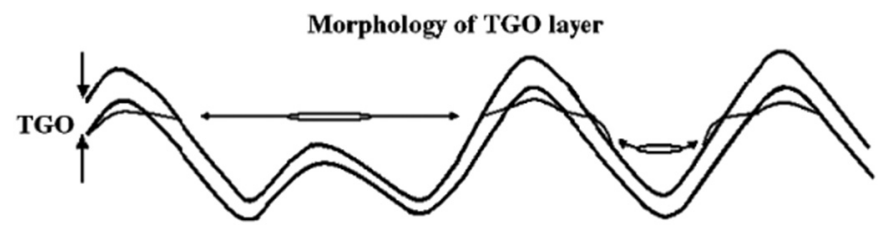

Fig. 13. Crack propagation behavior in the TBCs and its dependence on the morphology of the TGO layer and TC/BC interface [28].

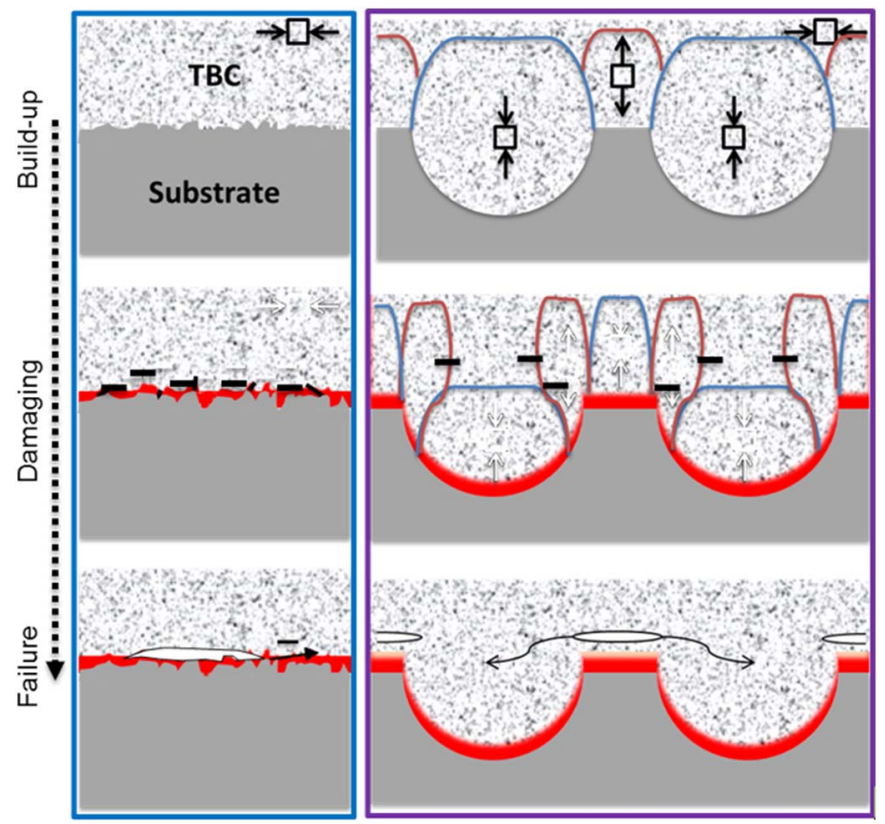

Fig. 14. Stresses and crack propagation in the TBC after cooling for flat and concave shape combined creep and oxidation.

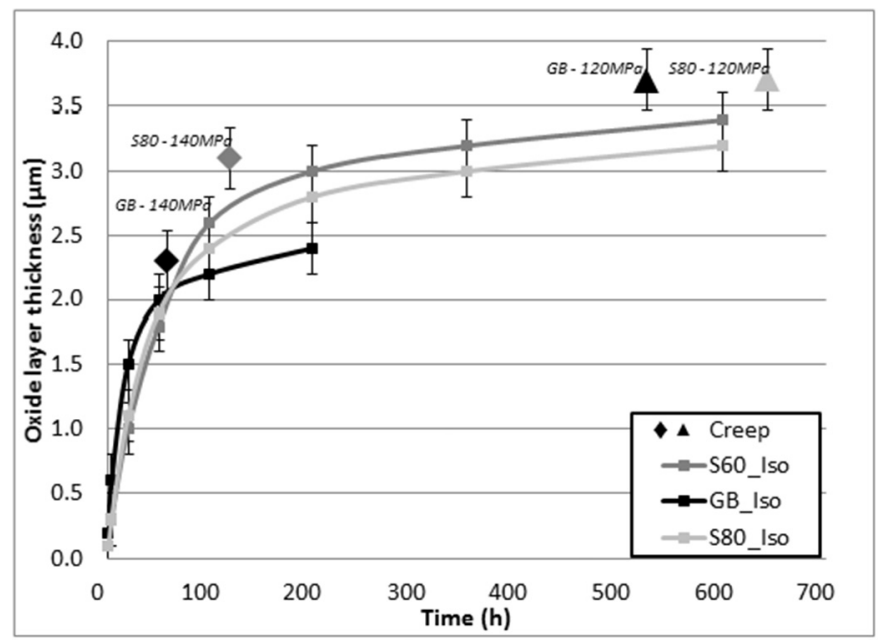

Fig. 15. TGO thickness evolution during isothermal and thermal cycling oxidation at $1100{ }^{\circ} \mathrm{C}$ for GB, S60 and S80. Data extracted after creep tests at $1100{ }^{\circ} \mathrm{C}$ have been added in this plot - three samples were evaluated for each thermal condition and surface preparation.

compared to both their stress free oxidation specimens. This could be due to the TGO in the meantime of creep elongation. Besides, for gritblasted samples, it can be deduced an oxide thickness limit for delamination under isothermal oxidation. Then, with stress imposed to the structure such as creep, stresses near the interface accelerated crack initiation and propagation. So, for low applied stress creep tests, the oxide thickness overcome the oxide thickness limit identified from pure oxidation tests. The duration of thermal exposure can be deduced as the main damaging mechanisms in this case. On the contrary, under $140 \mathrm{MPa}$, the oxide thickness was smaller. So, the mechanical applied stress favored the buckling mechanisms.

Finally, for similar creep strains, grit-blasted and laser textured samples have shown pronounced differences in terms of resistance to interfacial crack initiation. The patterns increased adhesion strength due to the complex interface morphology. Time to spallation was deduced to be equal to $1500 \mathrm{~h}$ under pure isothermal exposure, without any applied stress (Fig. 6). Despite a larger oxide thickness during creep 
tests under both 120 and 140 initial applied stresses, the interface was not damaged. The mechanical applied stress, under creeping tests, normally should increase the damaging mechanisms. It is hence suspected that the surface morphology changed the stress distribution near the interface and it seems to be benefic.

Future research will be dedicated to laser textured TBC systems with and without bond coat using APS and EB-PVD deposition processes for which failure mechanisms are different. Laser surface treatment strategy needs to be developed to enhance adhesion under thermomechanical solicitations. Topography could be optimized depending on the component (e.g. turbine blade) shapes, thermal gradients or materials.

\section{Conclusions}

The impact of the laser patterning on a bond-coat-less TBC coating system has been investigated at $1100^{\circ} \mathrm{C}$, during isothermal and thermal cycling oxidation, as well as during creep tests. According to this work, the following main conclusions can be established:

- Laser texturing of the substrate surface improve the time to spallation during both isothermal and thermal cycling creep tests at $1100{ }^{\circ} \mathrm{C}$ compared to a standard grit-blasting process.

- The grit-blasting induces surface recrystallization of the substrate, leading to an earlier onset of the tertiary creep stage.

- The improved time to spallation in creep and thermal cycling oxidation after laser patterning of the substrate results from a change in the top coat stress distribution, in addition to the growth of a dense and continuous inner $\alpha-\mathrm{Al}_{2} \mathrm{O}_{3}$ TGO.

\section{Acknowledgements}

The authors gratefully acknowledge the ANR (Agence National de la Recherche) for financial assistance in the ARCOLE (12-BS09-0009) project. A part of this study is conducted in the framework of the LABEX INTERACTIFS at Institut Pprime UPR CNRS 3346 under contract number ANR-11-LABX-0017.

\section{References}

[1] X.Q. Cao, R. Vassen, D. Stoever, Ceramic materials for thermal barrier coatings, J. Eur. Ceram. Soc. 24 (1) (Jan. 2004) 1-10.

[2] D.R. Clarke, S.R. Phillpot, Thermal barrier coating materials, Mater. Today 8 (6) (2005) 22-29.

[3] R. Eriksson, S. Sjostrom, H. Brodin, S. Johansson, TBC bonding coat top coat interface roughness, Surf. Coat. Technol. 51 (2013).

[4] T. Hüttel, Investigation of the High Temperature Performance of Thermal Barrier Coating Systems for Steam Turbine Applications, University of Aachen, 2010 (PhD thesis).

[5] J.A. Haynes, E.D. Rigney, M.K. Ferber, W.D. Porter, Oxidation and degradation of a plasma-sprayed thermal barrier coating system, Surf. Coat. Technol. 86 (1996) $102-108$.

[6] R.D. Jackson, The Effect of Bond Coat Oxidation on the Microstructure and Endurance of Two Thermal Barrier Coating Systems, University of Birmingham, 2010 (PhD thesis)

[7] T.M. Pollock, B. Laux, C.L. Brundidge, A. Suzuki, M.Y. He, Oxide-assisted degradation of Ni-base single crystals during cyclic loading: the role of coatings, J. Am. Ceram. Soc. 94 (2011) 136-145.

[8] M.A. Lafata, L.H. Rettberg, M.Y. He, T.M. Pollock, Oxidation-assisted crack growth in single-crystal superalloys during fatigue with compressive holds, Metall. Mater. Trans. A 41 (1) (2017) 1-12.

[9] K. Al-Athel, K. Loeffel, H. Liu, L. Anand, Modeling decohesion of a top-coat from a thermally-growing oxide in a thermal barrier coating, Surf. Coat. Technol. 222 (2013) 68-78.

[10] D. Balint, J. Hutchinson, An analytical model of rumpling in thermal barrier coatings, J. Mech. Phys. Solids 53 (4) (2005) 949-973.

[11] S.R. Choi, D. Zhu, R.A. Miller, Fracture behavior under mixed-mode loading of ceramic plasma-sprayed thermal barrier coatings at ambient and elevated temperatures, Eng. Fract. Mech. 72 (13) (2005) 2144-2158.

[12] A. Moridi, M. Azadi, G.H. Farrahi, Thermo-mechanical stress analysis of thermal barrier coating system considering thickness and roughness effects, Surf. Coat Technol. 242 (2014) 91-99.

[14] R. Kromer, J. Cormier, S. Costil, Laser surface patterning to enhance adhesion of plasma sprayed coatings surface and coatings technology, Surf. Coat. Technol. 278 (2015) 171-182.

[15] P. Caron, C. Ramusat, F. Diologent, Influence of the $\gamma^{\prime}$ fraction on the $\gamma / \gamma^{\prime}$ topological inversion during high temperature creep of single crystal superalloys, Proceedings of the 11th International Symposium on Superalloys, 2008, pp. $159-167$.

[16] R. Kromer, J. Cormier, S. Costil, Role of powder granulometry and substrate topography in adhesion strength of thermal spray coatings, J. Therm. Spray Technol. 25 (5) (2016) 933-945.

[17] R. Kromer, S. Costil, J. Cormier, L. Berthe, P. Peyre, D. Courapied, Laser patterning pretreatment before thermal spraying: a technique to adapt and control the surface topography to thermomechanical loading and materials, J. Therm. Spray Technol. 25 (3) (Feb. 2016) 401-410.

[18] A. Raffaitin, D. Monceau, E. Andrieu, F. Crabos, Cyclic oxidation of coated and uncoated single-crystal nickel-based superalloy MC2 analyzed by continuous thermogravimetry analysis, Acta Mater. 54 (17) (Oct. 2006) 4473-4487.

[19] L. Berthe, M. Arrigoni, M. Boustie, J.P. Cuq-Lelandais, C. Broussillou, G. Fabre, M. Jeandin, V. Guipont, M. Nivard, State-of-the-art Laser Adhesion Test (LASAT), 1 Taylor Francis, 2011, pp. 1-15.

[20] L. Berthe, R. Fabbro, P. Peyre, L. Tollier, E. Bartnicki, Shock waves from a waterconfined laser-generated plasma, J. Appl. Phys. 82 (6) (1997) 2826-2834.

[21] L.M. Barker, R.E. Hollenback, Laser inteferometer for measuring high velocities of any reflecting surface, J. Appl. Phys. 43 (1972) 4669-4674.

[22] R. Subramanian, Y. Mori, S. Yamagishi, M. Okazaki, Thermo-mechanical fatigue failure of thermal barrier coated superalloy specimen, Metall. Mater. Trans. A 46 (9) (Sep. 2015) 3999-4012.

[23] F. Riallant, J. Cormier, A. Longuer, X. Milhet, J. Mendez, High-temperature creep degradation of the AM1/NiAlPt/EBPVD YSZ system, Metall. Mater. Trans. A 45A (January) (2014) 351-359.

[24] J. Cormier, M. Jouiad, F. Hamon, P. Villechaise, X. Milhet, Very high temperatyre creep behavior of a single crystal Ni-based superalloy under complex thermal cycling conditions, Philos. Mag. Lett. 90 (8) (2010) 611-620.

[25] D. Poquillon, D. Oquab, D. Monceau, Cyclic oxidation kinetics modeling of NiAl single crystal, Mater. Sci. Forum 461 (2004) 737-746.

[26] E.N. Fedorova, D. Monceau, D. Oquab, S.A. Khudonogov, High-temperature oxidation of nickel-based alloys and estimation of the adhesion strength of resulting oxide layers, Prot. Met. Phys. Chem. Surf. 47 (3) (May 2011) 347-353.

[27] B. Albert, R. Volkl, U. Glatzel, High-temperature oxidation behavior of two nickelbased superalloys produced by metal injection molding for aero engine applications, Metall. Mater. Trans. A 45A (September) (2014) 4561-4572.

[28] D. Courapied, R. Kromer, L. Berthe, P. Peyre, S. Costil, J. Cormier, M. Boustie, $\mathrm{X}$. Milhet, Laser adhesion test for thermal sprayed coatings on textured surface by laser, Laser Appl. 28 (2) (May 2016).

[30] J.R. Vaunois, Modélisation de la durée de vie des barrières thermiques par le développement et l'exploitation d'essais d'adhérence, University of Grenoble, 2013 (PhD thesis).

[31] Y. Liu, Y. Liu, P. Lours, T. Sentenac, V. Vidal, Z. Wang, K. Ding, Influence of isothermal aging conditions on APS TBC's interfacial fracture toughness, Surf. Coat. Technol. 313 (2017) 417-424.

[32] X. Jichun, L. Jiarong, L. Shizhong, Surface recrystallization in nickel base single crystal superalloy D6, Chin. J. Aeronaut. 23 (2010) 478-485.

[33] V.V. Semak, J. Hopkins, M.H. McCay, T.D. McCay, A concept for a hydrodynamic model of keyhole formation, SPIE 2500 (1994) 64.

[34] M. Baker, T. Fiedler, J. Rosler, Stress evolution in thermal barrier coatings for rocket engine applications, Mech. Adv. Mater. Mod. Process. 1 (1) (Sep. 2015) 1-5.

[35] D.U. Furrer, H.J. Fecht, Gamma' formation un superalloy U720LI, Scr. Mater. 40 (11) (1999) 1215-1220.

[36] J. Meng, T. Jin, X. Sun, Z. Hu, Effect of surface recrystallization on the creep rupture properties of a nickel-base single crystal superalloy, Mater. Sci. Eng. A 527 (2010) 6119-6122.

[37] F. Riallant, J. Cormier, A. Longuet, X. Milhet, J. Mendez, High-temperature creep degradation of the AM1/NiAlPt/EBPVD YSZ system, Metall. Mater. Trans. A 45 (1) (Jan. 2014) 351-360.

[38] D. Monceau, B. Pieraggi, Determination of parabolic rate constants from a local analysis of mass-gain curves, Oxid. Met. 50 (6) (1998) 477-494.

[39] Y. Huang, X. Peng, The promoted formation of an $\alpha$-Al2O3 scale on a nickel aluminide with surface Cr2O3 particles, Corros. Sci. 112 (2016) 216-232.

[40] P. Audigié, Modelisation De l'interdiffusion Et Du Comportement En Oxydation Cyclique De Superalliages Monocristallins A Base De Nickel Revetus d'une SousCouche Gamma-Gamma' Riche En Platine. Extension Aux Systemes Barriere Thermique, University of Toulouse, 2015 (PhD thesis).

[41] R. Kromer, C. Verdy, S. Costil, H. Liao, Laser surface texturing to enhance adhesion bond strength of spray coatings - cold spraying, wire-arc spraying, and atmospheric plasma spraying, Surf. Coat. Technol. (2017) (in press).

[42] M. Ranjbar-Far, J. Absi, G. Mariaux, S. Shahidi, et al., Modeling of the residual stresses and their effects on the TBC system after thermal cycling using finite element method, Mater. Ceram. 62 (3) (2010) 275-279.

[43] H.E. Evans, M.P. Taylor, Delamination processes in thermal barrier coating systems, Corros. Sci. Eng. 6 (11) (2003). 